\title{
CISTO DE COLÉDOCO EM CRIANÇA
}

\author{
CHOLEDOCHAL CYST IN A CHILD
}

\author{
Artur Guimarães Filho, ACBC/CE \\ Simone Alves Frazão de Souza, $\mathrm{ACBC} / \mathrm{CE}^{2}$ \\ Vicente Pontes Carvalho ${ }^{3}$
}

\section{INTRODUÇÃO}

As variações anatômicas da disposição da árvore biliar são freqüentes, mas as anomalias congênitas da via biliar principal são excepcionais. A dilatação cística do colédoco é, depois da atresia, a anomalia anatômica mais frequiente.

O cisto de colédoco é uma doença rara com uma incidência entre 1:100.000 a 1:150.000 nascidos vivos. As mulheres são afetadas duas a quatro vezes mais que os homens ${ }^{1}$. A maioria dos casos apresenta-se na infância sendo $60 \%$ antes dos dez anos e $25 \%$ após os 20 anos $^{2}$. A tríade clássica de dor no quadrante superior direito do abdome, icterícia e massa abdominal palpável está presente em $15 \%$ a $45 \%$ dos pacientes .

Sua etiologia congênita ainda é discutida, propondo-se que a lesão seja resultado da junção anômala dos ductos pancreático e do colédoco durante o período embrionário $^{1-3}$

O diagnóstico da anomalia é feito através da opacificação da árvore biliar por via endoscópica ou transparieto-hepática, demonstrando na maioria dos casos um canal comum longo (em crianças maior que $4 \mathrm{~mm}$ e maior que $10 \mathrm{~mm}$ em adultos). Entre os meios diagnósticos empregados: tomografia, colangio-transparieto-hepática, colangiografia endoscópica, ressaltamos o valor da ultra-sonografia disponível na maioria dos hospitais e clinicas, pelo baixo custo, praticidade e por ser um método não invasivo.

O risco de transformação maligna desta doença aumenta com a idade, chegando a 14,5\% acima dos 20 anos $^{2}$.

Apresentamos um caso de cisto do colédoco tipo I da classificação de Alonso Lej e Todani, em paciente desnutrido, de 12,4 ×9,4cm, patologia de rara incidência em nosso meio, ressaltando seus aspectos clínicos, meios diagnósticos e terapêutica empregada, bem como o excelente resultado pós-operatório alcançado.

\section{RELATO DO CASO}

Criança de um ano e dois meses, sexo feminino, cor parda, desnutrida apresentando tumor de aumento progressivo em abdome superior há dois meses associado a empachamento pós-prandial e acólia fecal desde o nascimento.

Exame físico: desnutrida, ictéríca (+/4+), afebril, com volumosa massa palpável no abdome superior até o nível da crista ilíaca direita.

Durante a hospitalização apresentou infecção respiratória. Recebeu antibioticoterapia e hemotransfusão (300 $\mathrm{ml}$ de concentrado). Neste período observou-se aumento do volume do cisto, acentuação da leucocitose e do desconforto abdominal que permaneceram até a cirurgia. Exames laboratoriais:

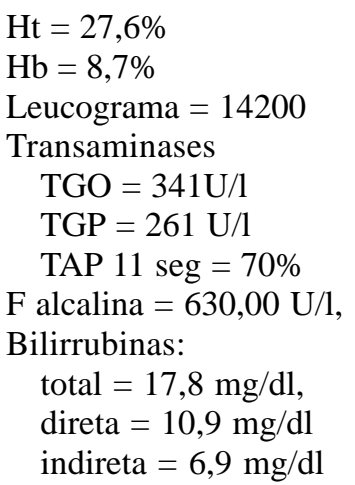

Raios X simples do abdome: opacificação difusa do quadrante superior direito.

Ultra-sonografia, mostrou imagem cística volumosa medindo 12,4 × 9,4cm (Figura 1), com dilatação das vias biliares intra-hepáticas, ducto hepático comum dila-

1. Cirurgião do Aparelho Digestivo da Santa Casa de Misericórdia de Sobral

2. Cirurgiã do Aparelho Digestivo da Santa Casa de Misericórdia de Sobral

3. Anestesiologista, Chefe da Anestesia da Santa Casa de Misericórdia de Sobral

Recebido em 30/07/2001

Aceito para publicação em 24/10/2001

Trabalho realizado na Santa Casa de Misericórdia de Sobral-CE. 


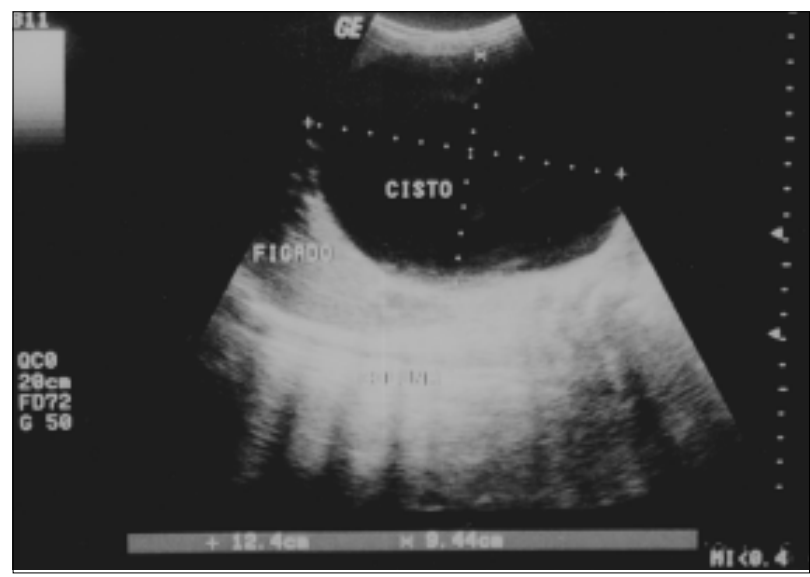

Figura 1 - Cisto gigante de colédoco em criança.

tado (10mm) e vesícula biliar normal. A tomografia do abdome confirmou os achados do ultra-som.

A laparotomia (incisão subcostal bilateral) mostrou volumoso cisto iniciando-se abaixo da bifurcação dos ductos hepáticos até o colédoco retroduodenal, bastante aderido ao estômago e cólon. Após aspiração parcial do conteúdo do cisto $(500 \mathrm{ml})$ e identificados os vasos do hilo hepático (artéria hepática e veia porta) o cisto foi ressecado completamente, sendo o trânsito reconstituído com anastomose bilio-digestiva em Y de Roux.

O pós-operatório ocorreu com fistula biliar de baixo débito que fechou espontaneamente. A infecção da ferida foi controlada com antibióticos e cuidados locais. A gastroparesia prolongou-se por oito dias e foi corrigida com sondagem nasogástrica e reposição hidreletrolítica.

Recebeu alta no $18^{\circ}$ dia de pós-operatório, com melhora do estado geral, ativa, aceitando bem a alimentação.

O exame macroscópico da peça mostrou mucosa esverdeada e aveludada e paredes de $3 \mathrm{~mm}$ de espessura (Figura 2). Exame microscópico: cisto com perda do seu revestimento epitelial, paredes fibrosas com moderada exsudação de polimorfonucleares. Vesícula biliar com paredes preservadas e mucosas edemaciadas.

\section{DISCUSSÃO}

A primeira descrição clinica de um paciente com cisto de colédoco foi apresentada por Douglas em 1852.

Apesar da origem do cisto ser controversa, a teoria mais aceita para explicá-la, é a proposta por Babbit ${ }^{1}$ e se baseia na união anômala dos ductos colédoco e pancreático. Segundo esta hipótese, a união destes dutos ocorrendo acima do mecanismo esfincteriano da papila e formando um canal comum longo predisporia às alterações encontradas, através do refluxo do suco pancreático para o colédoco de menor pressão. $\mathrm{O}$ suco pancreático na presença da bile originaria produtos agressivos desencadeando agressão aos constituintes da parede do colédoco que culminariam nas alterações encontradas. A incidência na literatura de ducto comum longo em pacientes com cisto de colédoco varia de $40 \%$ a $100 \% 4$, reforçando esta teoria.

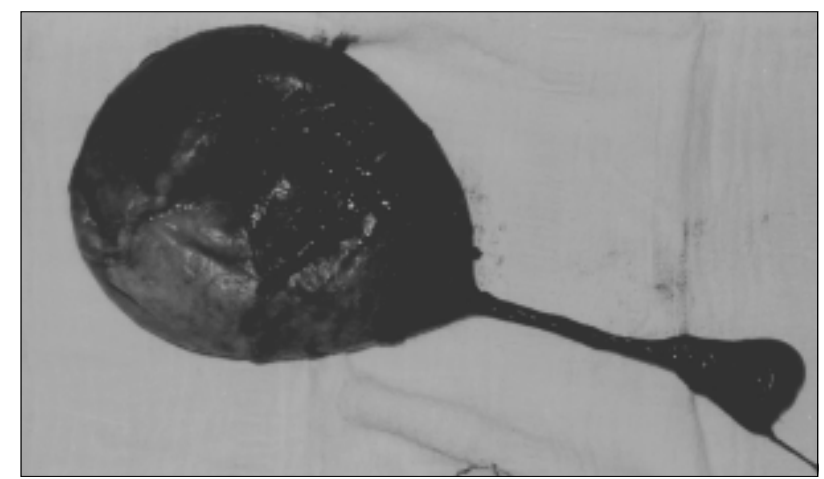

Figura 2 - Cisto gigante de colédoco em criança.

Alonso-Lej em 1959, inicialmente e, posteriormente, Todani em 1977, classificaram os cistos em cinco tipos: Tipo I (dilatação fusiforme do colédoco); Tipo II (divertículo do colédoco); Tipo III (coledococele); Tipo IVa e IVb (associação intra-hepático, extra-hepático ou intra-hepático e coledococele) e o Tipo V (doença de Caroli) ${ }^{2,3}$.

O diagnóstico pode se realizar em qualquer idade, porém na maioria das vezes se efetua antes dos dez anos; $20 \%$ a $25 \%$ depois dos 20 anos e somente $8 \%$ acima dos 40 anos. A manifestação clínica de icterícia, dor e massa palpável descrita ocorre de $13 \%$ a $68 \%$ dos casos. Em dois terços dos casos podem surgir sintomas tais como: vômitos, febre e/ou complicações como pancreatite, peritonite por rotura do cisto, insuficiência hepática por cirrose biliar, sepse etc.

A associação do cisto de colédoco com neoplasia tem sido mencionada por alguns autores ${ }^{2-4}$. Kasai et al. ${ }^{5}$ foram os primeiros que comunicaram o aumento da incidência de câncer que ocorre nos cistos e defenderam sua excisão cirúrgica. Voyles ${ }^{4}$ revisou 1.433 casos com cisto em vias biliares dos quais $4,6 \%$ tinham câncer e $76 \%$ correspondiam a adultos. Neste estudo o risco para neoplasia se viu afetado segundo a idade da seguinte maneira: $0,7 \%$ para a idade menor que dez anos; $6,8 \%$ para idade entre 11 e 20 anos e 14,5\% para os maiores de 20 anos. Em geral a incidência de câncer em via biliar associado a cisto de colédoco oscila entre $23 \%$ e $39,4 \%$, muito mais alto do que na população geral $(0,003 \% \text { a } 0,004 \%)^{4}$.

Entre os meios de diagnóstico empregados, a colangiografia transpapilar mostra o canal comum longo, além da identificação do cisto e dos canalículos intra-hepáticos. A tomografia, a cintilografia e, especialmente, a colangiografia transparietal têm sido utilizados como métodos complementares de diagnóstico valiosos.

A ultra-sonografia tem se mostrado bastante útil (Figura 1). É um método prático, de baixo custo, identificando com relativa precisão as dimensões, contornos, características e topografia da lesão, além de fornecer informações sobre as vias biliares intra e extra-hepáticas. Neste caso foi utilizada somente a ultra-sonografia como único recurso de imagem, para diagnóstico e indicação cirúrgica da anomalia, associado ao quadro clínico sugestivo. A tomografia do abdome apenas confirmou os achados ultra-sonográficos. 
Em função de sua associação com câncer, a maioria dos autores tem proposto a ressecção do cisto com anastomose hepático-jejunal ou hepático-duodenal. Os casos não operados podem evoluir para obstrução biliar completa, cirrose biliar secundária, hipertensão e colangite séptica por infecção grave.

Neste caso foi realizada ressecção completa do cisto juntamente com a vesícula biliar e reconstrução do trânsito com anastomose hepático-jejunal em Y-de-Roux. Apesar do estado de desnutrição, do quadro infeccioso respiratório pré-operatório e da infecção do cisto, a recuperação da paciente se deu de modo satisfatório, com um bom resultado pós-cirúrgico imediato.
Concordamos com a opinião da maioria dos autores que recomendam a ressecção cirúrgica do cisto de colédoco tipo I e II, seguido de reconstrução do trânsito a Y de Roux nos casos do tipo I. A preservação do cisto com anastomose cistoentérica não é recomendada devido ao alto risco de estenose na anastomose, e complicações subseqüentes como cirrose biliar, colangite e malignização. Nos pacientes com cisto tipo III o tratamento recomendado é a papiloesfincterectomia endoscópica. Nos casos em que há comprometimento da arvore biliar intra-hepática os procedimentos variam desde hepatectomias segmentares até o transplante hepático nos casos em que há comprometimento extenso da árvore biliar intra-hepática.

\begin{abstract}
We report the case of a one-year and two-months-old child with a choledochal cyst tYpe I of Alonso-Lej and Todani's classification, diagnosed through abdominal ultrasound. The surgical treatment was cholecistectomy and choledochal cyst excision with Roux-in-Y hepatic-jejunostomy. Minor complications were observed during early postoperative recovery. Long-term flow-up has been uneventiful, with overall improvement.
\end{abstract}

Key Words: Choledochal cyst; Obstrutive jaundice; Cholangitis.

\title{
REFERÊNCIAS
}

1. Babbit DP. Congenital choledochal cyst: new etiological concept based on anomalous relationship of common bile duct and pancreatic bulb. Ann Radiol 1969;12:231240.

2. Tannuri U, Pessoa JHL, Sakane PT, Gonçalves M E P, Bedoni F. Dilatação da via biliar e anomalia da junção dos ductos colédoco e pancreático principal na criança. J Pediatria,1994;70(6):359 - 364.

3. Martinez DG, Minian IZ. Riesgo de neoplasia en adultos con quiste de colédoco.Rev Med IMSS 1999; 37(4):257-262

4. Voyles C, Smadja C, Shands W, Blumgart L. Carcinoma in choledochal cyst. Age related incidence. Arch Surg 1983;118:986-988
5. Kasai M, Asakura Y, Taira Y. Surgical treatment of choledochal cyst Ann Surg. 1970; 172: 844-51.

Endereço para correspondência:

Artur Guimarães Filho

Av. D. José, 800 - Centro

62.010-290 - Sobral-CE 